University of New Haven

University of

New Haven

Digital Commons@ New Haven

$3-2013$

\title{
Disentangling the Effects of Violent Victimization, Violent Behavior, and Gun Carrying for Minority Inner-City Youth Living in Extreme Poverty
}

Richard Spano

University of New Haven, RSpano@newhaven.edu

John Bolland

University of Alabama - Tuscaloosa

Follow this and additional works at: http://digitalcommons.newhaven.edu/criminaljustice-facpubs Part of the Criminology and Criminal Justice Commons

\section{Publisher Citation}

Spano, R., \& Bolland, J. (2010). Disentangling the Effects of Violent Victimization, Violent Behavior, and Gun Carrying for Minority Inner-City Youth Living in Extreme Poverty. Crime \& Delinquency, 59(2), 191-213.

\section{Comments}

This is the authors' accepted manuscript ("post-print") of the article that appeared in Crime \& Delinquency, 59(2), 191-213, http://cad.sagepub.com/ content/59/2/191.refs, Copyright (C) 2015 by SAGE Publications. The published article may be accessed here . 
Spano, R. \& Bolland, J. (in press). Disentangling the effects of violent victimization, violent behavior, and gun carrying for minority inner city youth living in extreme poverty. Crime $\&$ delinquency.

\author{
Abstract: Two waves of longitudinal data were used to examine the sequencing between violent \\ victimization, violent behavior, and gun carrying in a high poverty sample of African American \\ youth. Multivariate logistic regression results indicated: (1) violent victimization T1 and violent \\ behavior T1 increased the likelihood of initiation of gun carrying T2 when examined separately (by \\ $132 \%$ and $91 \%$ respectively). However, only violent victimization T1 was a significant predictor of \\ initiation of gun carrying T2 after controlling for violent behavior T1. More nuanced analyses \\ uncovered no significant difference in the likelihood of initiating gun carrying when comparing \\ offensive versus defensive gun carriers. The theoretical and policy implications of these findings are \\ also discussed.
}


National trends in youth violence have been declining since a peak in the early 1990s (Bureau of Justice Statistics, 2004). In addition, more recent national trends in gun carrying from the Youth Risk Behavior Survey (CDC, 2007) show that gun carrying among youth declined between 1993 and 1999 and remained stable from 1997 to 2007 . However, the rate of physical injury since the early 1990s (1991 to 2007) have remained stable in this nationally representative sample of high school students (CDC, 2007). In addition, Cook and Laub (2002) noted that use of guns in homicides after the peak in youth violence in the early 1990s has dropped very little during the late 1990s and gun use in homicides has increased for several types of homicides (felony-type and gang related) during the late 1990s. As a result, the Centers for Disease Control has advocated for the reduction and/or elimination of gun carrying among youth to prevent firearm injuries and fatalities, which would have a substantial impact on reducing the level of youth violence within high poverty, inner city neighborhoods (Rivara, 2002).

The CDC recommendation is not surprising given that both state and national laws prohibit unsupervised gun carrying by youth due to their lack of maturity and a propensity to engage in violent behavior (Cook \& Ludwig, 2004). However, we could find no studies that have attempted to disentangle the effects of violent victimization, violent behavior, and gun carrying among inner city youth. One reason for this oversight is that most individual level studies of the determinants of gun carrying utilize cross-sectional data (e.g., Cao et al., 1997), which include a handful that have focused specifically on youth gun carrying (e.g., Sheley \& Wright, 1993). Several longitudinal studies using the Rochester Youth Development Study (RYDS) data have focused on gun carrying by adolescents, but have not simultaneously examined the impact of violent victimization and violent behavior on gun carrying (Lizotte et al. 2000; Lizotte et al. 1994). As a result, it is unclear if gun carrying is a consequence of violent victimization and/or violent behavior (Spano et al., 2008). 
In addition, no studies have examined the initiation of gun carrying among inner city youth. This is a surprising oversight given the importance of primary prevention of gun injury and violence in the field of public health. The identification of the determinants of first time gun carrying is the most logical starting point to drastically reduce both gun carrying and gun related violence among inner city youth. Focusing on the initiation of gun carrying also represents a logical starting point to disentangle the effects of violent victimization and violent behavior on gun carrying for urban adolescents.

Finally, the broader gun control debate can provide a framework for the examination of the impact of violent victimization, violent behavior, and gun carrying among inner city youth. On the one hand, gun carrying could be triggered by violent victimization as youth living in extreme poverty initiate gun carrying to prevent future violent victimization (e.g,. Kleck, 1988). On the other hand, youth could be motivated to carry guns to better frighten and intimidate victims based on a history of prior violent behavior (Wright \& Rossi, 1986). The political debate around gun control typically polarizes the electorate during upswings in violent crime (Blendon et al., 1996). However, a large body of literature has documented a significant overlap between victim and offender groups (e.g., Singer, 1981). Since no studies have simultaneously examined the effects of violent victimization and violent behavior on gun carrying among adolescents using longitudinal data, we cannot determine: (1) the prevalence of offensive versus defensive gun carrying; and,(2) the independent effects of violent behavior and violent victimization on the decision to carry a gun for the first time.

Given the lack of longitudinal data on the impact of violent victimization and violent behavior on gun carrying, this paper has two overarching goals: (1) to establish the developmental sequencing of violent victimization, violent behavior, and initiation of gun carrying; and (2) to isolate the effects of violent victimization and violent behavior on gun carrying among urban youth. First, routine activities theory will be used to explain how violent victimization and violent behavior 
motivate inner city youth to carry guns. Next, the criminal career approach (CCA) and the public health literature will be used to illustrate the utility of studying the initiation of gun carrying to disentangle the effects of violent victimization, violent behavior, and gun carrying by adolescents. Third, the "artificial dichotomy" between victims and offenders will be discussed (Jensen \& Brownfield, 1986) to demonstrate why it is important to include measures of violent victimization as well as violent behavior to increase our understanding of youth gun carrying. Finally, we examine the impact of violent victimization and violent behavior on the initiation of gun carrying using two waves of the Mobile Youth Survey, which is a longitudinal sample of inner-city minority youth living in extreme poverty.

\section{HOW DOES VIOLENT VICTIMIZATION AND VIOLENT BEHAVIOR INFLUENCE GUN CARRYING AMONG URBAN YOUTH LIVING IN POVERTY?}

The concentration of violence in high poverty neighborhoods presents a unique challenge for urban minority youth (Acosta et al. 2001). The dangers of living in extreme poverty also provide the clearest illustration of the motivations that underlie gun carrying for protection (given the high risk of violent victimization) and gun carrying by criminals (given the high rates of violent crime in these areas). Routine activities theory provides a framework to discuss the motivations for gun carrying among urban youth living in extreme poverty (Spano et al., 2008).

On the one hand, violent victimization can trigger defensive gun carrying as youth attempt to protect themselves from future incidents of violent victimization. According to routine activities theory, gun carrying can be categorized as a source of individual level guardianship in response to violent victimization (Spano et al., 2008). Similarly, Cao et al. (1997) described how individuals can respond to violent victimization by acquiring firearms. Although an overreliance on cross-sectional data has prevented researchers from disentangling the effects of violent victimization on gun carrying among students (Cao et al., 1997), this sequence of events (violent victimization $\rightarrow$ gun 
carrying) has some empirical support since victims who carry guns are less likely to be injured compared to victims who either do not resist or who resist without a weapon (Kleck, 1988). Tark and Kleck (2004) argued that all individuals are guardians of their own safety who take action to reduce the likelihood of injury from violent crime. In this paper, we argue that the sequencing of violent victimization T1 $\rightarrow$ initiation of gun carrying T2 is an example of defensive gun carrying as a source of guardianship in response to violent victimization.

Routine activities theory can also be used to illustrate the opposing viewpoint: that initiation of gun carrying is triggered by a deviant (i.e., criminal) lifestyle. More specifically, guns are useful to intimidate and control victims when criminals commit crimes (Wright \& Rossi, 1986). One key finding from Sheley and Wright's (1993) study of serious juvenile offenders was that firearm ownership was strongly related to violent behavior. More importantly, Sheley and Wright (1993: 81) also recognize the challenge of determining the causal direction of the gun-crime relationship because it is just as likely that gun carrying leads to violent crime as it is that violent crime triggers gun carrying. Although their cross-sectional study could not determine the causal sequencing between violent crime and gun carrying, they highlighted the importance of gun possession by predatory criminals as a key "tool of the trade" that can be used to intimidate potentially aggressive victims, to prevent violent attacks from armed victims, and/or to enable the youth to escape from a crime scene. Similarly, Webster et al.'s (1993:1607) survey of students in two inner city junior high schools found that the majority of arrested youths carried guns and conclude that "gun carrying could more realistically be explained as part of an extremely aggressive, rather than defensive, system of thought and behavior."

Although recent research has highlighted the challenges of specifying the motivation of weapon/gun carrying (Brennen \& Moore, 2009), the connection between violent behavior and gun carrying (especially by youth) has remained a concern for both policy makers and criminologists. 
The primary reason for this concern is evidence of a "weapon instrumentality effect" where the use of weapons increases the likelihood of injury and death during violent felonies (see Cook, 1991 for a review). However, longitudinal studies have not focused on the role of violent behavior as a precursor to gun carrying by urban youth living in extreme poverty (Brennan \& Moore, 2009). The next section explores this issue in more detail by describing how a closer examination of the precursors of the initiation of gun carrying is a logical starting point for the primary prevent of gun related violence by youth.

\section{THE UTILITY OF FOCUSING ON INITIATION OF GUN CARRYING}

Given the high levels of violent crime, violent victimization, and gun carrying in high poverty neighborhoods, it is surprising that researchers have not examined the developmental sequencing between these three interrelated phenomenon. However, insights from the career criminal and public health literature provide a framework to disentangle the effects of violent victimization and violent behavior on gun carrying by examining initiation of gun carrying among urban youth to increase our understanding of the determinants of first time gun carrying by youth. The criminal career approach (CCA) has argued that initiation of criminal behavior is a critical area for research because increasing our understanding about the precursors of initiation of criminal offending is a key first step toward developing interventions and preventing criminal behavior (Piquero et al. 2007). More importantly, CCA's focus on initiation of criminal behavior dovetails with public health's focus on primary prevention of violence given the severity of health consequences (e.g., injury and death) associated with gun carrying and violence (Rivara, 2002). The first step in the process of breaking the linkage between violence and gun carrying among adolescence is to utilize prospective longitudinal data to increase our knowledge about how violent behavior develops in youth (Dodge, 2001). Ash et al. (1996) concluded in their study of gun acquisition and use by juvenile offenders that increased knowledge about developmental patterns of 
gun carrying among delinquents would be a critical component in developing effective strategies to reduce firearm violence. Kellerman et al. (1991) applied the public health model to the prevention of firearm injuries and argued that the most logical starting point for preventing firearm violence is by focusing on the pre-event stage, which is consistent with CCA's focus on the determinants of initiation of serious predatory violence (Blumstein et al., 1988).

\section{ARE VICTIMS AND OFFENDERS MUTUALLY EXCLUSIVE?}

The previous two sections have highlighted the importance of violent victimization and violent behavior as critical determinants of initiation of gun carrying among urban youth. These two factors represent two ends of the spectrum of the gun control debate. In other words, youth who initiate gun carrying after engaging in violent behavior are carrying guns for offensive purposes while youth who are victims of violence are examples of defensive gun carrying. Politicians typically polarize the distinction between offensive and defensive gun carrying by highlighting the role of violent offending or violent victimization on gun carrying. However, Jensen and Brownfield (1986) critiqued the "artificial dichotomy" between victim and offender groups using routine activities theory and argued that criminal routines are highly intercorrelated with victimization risk. Similarly, Sampson and Lauritsen (1990) and Lauritsen, Sampson and Laub (1991) found a strong connection between offending and victimization in a longitudinal national probability sample of U.S. youth as well as a national survey in England in Wales.

In short, the overlap between victim and offender groups provides a third category to consider when studying the determinants of gun carrying among urban youth. Given that there is a strong relationship between victimization and offending, the question is not whether some youth that carry guns will be both victims and offenders; it is how many youth fall into this category, which has not been examined in previous studies of gun carrying among adolescents (McDowall, 1995). 
An additional benefit of simultaneously examining the impact of violent victimization and violent behavior on gun carrying is that it will enable us to categorize youth based on different combinations of victimization and/or violent behavior. For example, youth who are only victims and/or have no history of victimization or violent behavior represents a clear example of defensive gun carrying, while youth who are only violent offenders are prime candidates for offensive gun carrying given the developmental sequencing between violent behavior and gun carrying. Given the lack of individual research in this area, we do not know: (1) the prevalence of offensive versus defensive gun carrying among urban youth; (2) the independent effects of different combinations of violent victimization and violent behavior on initiation of gun carrying; or (3) the likelihood of defensive versus offensive gun carrying among youth living in extreme poverty.

\section{RESEARCH QUESTIONS}

This paper will examine three research questions. First, do violent victimization and violent behavior T1 increase the likelihood of initiation of gun carrying T2 among urban youth? Second, what is the level of overlap between victims and offenders? Finally, what is the impact of different combinations of violent victimization and violent behavior T1 (e.g., victim only, offender only, both victim and offender, neither victim nor offender) on the initiation of gun carrying T2?

\section{DATA}

This study utilizes two waves of longitudinal data collected in 2000 and 2001 as part of a large, ongoing community-based study of adolescent risk behavior called the Mobile Youth Survey (or MYS) (see Spano et al. 2006). Youths age 9 to 19 living in twelve high poverty neighborhoods in Mobile, Alabama (1990 poverty levels between 57\% and 91\%) were targeted for this multiple cohort study. Half of these neighborhoods were public housing. The Mobile and Prichard Housing Authorities provided a list of addresses where the lease listed youths between age 10 and 18. The MYS targeted $50 \%$ of these apartments and contacted the leaseholder in each of these public 
housing residences over an 11 week period to verify that appropriately aged youths lived in the residence. The youth(s) was (were) asked to participate and the caregiver was asked to sign a consent form. Non-targeted residences were permitted to participate with parental consent. Youths were then scheduled to attend a group-administered survey. Participants were promised confidentiality and paid $\$ 10$ for their participation.

The survey was administered annually during the afternoon and early evenings. Parents or caregivers were not allowed in the room during the administration of the survey. Questions were read aloud to younger respondents to enable respondents with poor reading ability to complete the survey. When respondents did not understand a question, it was explained to the group by a survey administrator or to the individual by monitors in the room. Older respondents who appeared to have difficulty reading were invited to a separate area where questions were read to them individually or in a very small group.

The MYS uses a community epidemiology framework (Kellam \& Van Horn, 1997) that limits the effects of neighborhood and individual level poverty by restricting the study to respondents who are homogeneous on those factors. This sampling procedure is well-suited for epidemiological studies of violent victimization given the concentration of violence and violent victimization in high poverty, urban. More importantly, unlike other longitudinal studies (e.g., Rochester Youth Development Study), the MYS is a community based sample that does not require school attendance for inclusion in the sample.

\section{BRIEF DESCRIPTION OF THE LONGITUDINAL SAMPLE}

The MYS surveyed 2164 youth from 1733 households (average number of respondents per household ranged from 1 to 6 youth). About 61.6\% of the 2164 MYS youth who participated T1 lived in public housing during T1. About 66\% (or 1428 youth) completed the MYS for both T1 and T2, while 34\% (or 726 youth) dropped out between T1 and T2. Out of the 1428 youth who are 
candidates for the two wave longitudinal model, the analysis focused on the 1049 youth who participated in the MYS during T2 and also were potential candidates for initiating gun carrying T2. More specifically, the analysis focused on youth who: (1) did not carry a gun T1; and (2) answered "no" when asked if they had ever carried a gun T1.

\section{LIMITATIONS OF THE MYS}

Although the MYS provides a unique opportunity to examine the determinants of violent victimization in a high poverty setting, there are several limitations that should be highlighted. First, $96.4 \%$ of the two wave sample was African American so all whites were dropped from the current analysis. As a result, the findings cannot be generalized to white youth who live in these high poverty neighborhoods.

A second limitation is due to the community epidemiology framework. The MYS is best described as a multiple cohort study conducted in 12 high poverty neighborhoods. Data collection focused on maximizing the sample size for each wave of data collection to give maximum insight into the lives of these youth living in these neighborhoods. A secondary benefit was that some MYS respondents were surveyed more than once. One difference between the MYS and other longitudinal data collection projects (i.e., RYDS) is that the MYS does not have a targeted longitudinal sample. In other words, the primary goal of the MYS was not to minimize sample attrition in the longitudinal sample. The longitudinal sample is a by-product of the multiple cohort design rather than a central justification for data collection in this high poverty context.

Another (related) limitation is the rate of sample attrition in the 2 waves of the MYS used in this study. Although sample attrition is a common problem associated with longitudinal data collection (Brame \& Paternoster, 2003), the substantive importance of sample attrition is its potential to bias parameter estimates for the prevalence and frequency of delinquency and drug use (Thornberry et al., 1993). Given these concerns, analyses were conducted to determine if the $36.4 \%$ 
rate of sample attrition produced a nonrepresentative subsample of respondents. A multivariate logistic regression equation was estimated where the independent variables used in this analysis (see variable descriptions and descriptive statistics in Table 1 below) as well as place of residence (i.e., if the youth lived in public housing) were regressed on whether or not the respondent dropped out of the sample. The findings from this multivariate model indicate: (1) sex, level of parental monitoring, living with two parents, violent behavior, gang membership, gun carrying, drug and alcohol use, and employment are not significant predictors of dropout; and (2) only age and living in public housing are significant predictors of dropout at the .05 level. More specifically, older respondents are more likely to drop out of the sample while youth living in public housing were less likely to drop out (results available upon request). Additional bivariate chi-square analyses also indicated that the dependent variable (gun carrying) was not a significant predictor of whether a respondent dropped out of the sample (results available upon request). Given this pattern of results, we conclude that sample attrition has not produced a systematic bias in the longitudinal data used in the current analysis.

\section{DEPENDENT VARIABLE}

Descriptive statistics and variable descriptions for the independent and dependent variables are listed in Table 1. The dependent variable (initiation of gun carrying T2) was created from two items on gun carrying included in the MYS. The first item (whether the respondent carried a gun during the past 90 days) was a measure of the prevalence of gun carrying during T2. The second item was the lifetime prevalence of gun carrying T1. Youth who had no history of gun carrying based on the measure of lifetime prevalence of gun carrying T1, but indicated that they had carried a gun during the past 90 days T2 were included in our measure of initiation of gun carrying T2 (1=yes). About $8 \%$ of MYS youth initiated gun carrying T2.

$$
\text { //***Table } 1 \text { about here***// }
$$




\section{INDEPENDENT VARIABLES}

The independent variables are divided into two categories: key independent variables (violent victimization T1 and violent behavior T1) and control variables. The first key independent variable is violent victimization T1. The prevalence of violent victimization (coded $1=y e s)$ is measured by three items: (1) were you threatened with a knife or gun during the past 90 days? (2) were you cut bad enough to see a doctor in the past year? (3) were you shot at during the past year?. About 17\% of MYS youth were a victim. The second key independent variable is the prevalence of violent behavior T1 (coded 1=yes), which is measured by four items: (1) did you threaten someone with a knife or gun in the past 90 days? (2) have you fought someone in the past 90 days? (3) have you pulled a knife or a gun on someone in the past 90 days? (4) have you cut someone bad enough to require a doctor's visit in the past year? About 43\% of MYS youth engaged in violent behavior during T1.

The next part of Table 1 gives the prevalence of different combinations of violent victimization and violent behavior T1 based on the measures listed above. More specifically, about $5 \%$ were victims only $\mathrm{T} 1,32 \%$ engaged in violent behavior, but were not victimized, about $12 \%$ were both a victim and offender, and over half (52\%) were neither victims nor offenders. Four control variables are also listed in Table 1. Respondent age T1 ranged between 9 and 19 with an average of 13.1 . About $42 \%$ of MYS youth are males and about $30 \%$ lived in two parent households T1. Approximately 13\% felt unsafe in their neighborhood all the time. Finally, about 3\% of youth were actively involved in a gang.

\section{ANALYSIS PLAN}

In the first part of the analysis, logistic regression is used to determine the impact of violent victimization T1 and violent behavior T1 on the likelihood of initiation of gun carrying T2 net of

controls. Separate multivariate models are estimated for violent behavior T1, violent victimization 
T1, and then a model that includes violent victimization T1 and violent behavior T1. Since no studies have simultaneously examined the role of both violent victimization and violent behavior on gun carrying using longitudinal data, our objectives were (1) to replicate the previous research that has typically focused on either violent victimization or violent behavior; and (2) to determine if both were significant predictors of initiation of gun carrying T2 (or if the effects of one of these two factors became non-significant once the other was controlled for). Next, the descriptive statistics of the different combinations of youth who engage in violent behavior and/or are victims of violence are depicted in a Venn diagram to illustrate the overlap between victimization and violent behavior among MYS youth. Finally, the second part of the analysis is a more nuanced examination of the effects of violent victimization, violent behavior, and gun carrying. Multivariate logistic regression was used to examine how each combination of violent victimization and violent behavior T1 affected the likelihood of initiation of gun carrying T2. Our goal is to determine if youth who are victims of violence are more or less likely to initiate gun carrying compared to youth who are engaging in violent behavior.

\section{RESULTS}

\section{ARE VIOLENT VICTIMIZATION AND/OR VIOLENT BEHAVIOR RISK FACTORS FOR INITIATING GUN CARRYING?}

Table 2 contains the odds ratios from logistic regression equations to examine the impact of violent victimization T1 and violent behavior T1 on the initiation of gun carrying T2. Equation one in Table 2 examines the impact of violent victimization T1 on the likelihood of initiation of gun carrying T2 net of controls for age, sex, family structure T1, and gang membership T1. The results are consistent with proponents of defensive gun carrying: youth who are victims of violence T1 are $132 \%$ more likely to initiate gun carrying T2 $(\mathrm{p}<.001)$. Equation two examines the impact of violent behavior T1 on the initiation of gun carrying T2 net of controls. The results are also consistent with offensive gun carrying: youth who engage in violent behavior T1 are $91 \%$ more likely to initiate gun 
carrying T2 ( $<.01)$. Equation three includes both violent victimization T1 and violent behavior T1 and indicates that youth who are victims of violence T1 are still at increased risk for initiation of gun carrying T2, but the effect for violent behavior T1 changes from positive and significant in equation two to non-significant in equation three. In short, the findings from equation three in Table 2 indicate that victims of violence T1 are 110\% more likely to initiate gun carrying T2 after controlling for violent behavior T1, which suggests that defensive gun carrying is a critical factor to explain first time gun carrying among urban youth living in extreme poverty.

$$
\text { //***Table } 2 \text { about here***// }
$$

\section{OVERLAP BETWEEN VICTIMS AND OFFENDERS}

Figure 1 contains a Venn diagram to supplement the descriptive statistics in Table 1, which overview the different combinations of victimization and violent behavior among MYS youth. The

two spheres in the Venn diagram represent the intersection of victimization (the smaller sphere) and violent behavior (the larger sphere). There are several findings of interest. First, the "victimization sphere" is almost totally eclipsed by the "violent behavior sphere." In other words, the first part of Table 1 shows that $16.5 \%$ of MYS youth were victims of violence. However, the overlap between the victimization and violent behavior spheres in Figure 1 shows that $11.6 \%$ out of the $16.5 \%$ of MYS youth who are victims of violence are also engaging in violent behavior. In addition, only a small proportion of MYS youth are only victims of violence (4.9\%). In other words, over two thirds $(70.3 \%$ or $11.6 \% / 17 \%$ ) of youth who are victims of violence are also engaging in violent behavior and a smaller percentage of MYS youth (4.9\%) are potential candidates for defensive gun carrying that are untainted by participation in violent acts. Second, a majority of MYS youth are able to avoid: (a) becoming victims of violence; as well as (b) engaging in violent behavior (52.4\%). Finally, violent behavior is common among MYS youth, but not all MYS youth who engage in violent 
behavior are also victims of violence (i.e., the larger "violent behavior sphere" that does not intersect with the "violent victimization sphere").

$$
\text { //***Figure } 1 \text { about here } * * * / /
$$

\section{THE IMPACT OF DIFFERENT COMBINATIONS OF VIOLENT VICTIMIZATION AND VIOLENT BEHAVIOR T1 ON THE INITATION OF GUN CARRYING T2}

Table 3 contains a more detailed breakdown of the effects of violent victimization T1 and violent behavior T1 on the initiation of gun carrying T2. Equation one examines the effects of each combination of victimization and violent behavior T1 on the initiation of gun carrying T2 after controling for age, sex, family structure T1, fear of crime T1, and gang membership T1. The comparison group for the key independent variables in equation 1 (only victimization T1, only violent behavior T1, both victimization and violent behavior T1) is the "neither" category, which are youth who were neither victimized nor engaging in violent behavior T1. The findings indicate that all three combinations of victimization and violent behavior T1 are significant risk factors for initiation of gun carrying T2. More specifically, youth who are only victims T1 are 238\% more likely to initiate gun carrying T2 $(\mathrm{p}<.01)$, youth engaging in violent behavior only T1 are $90 \%$ more likely to initiate gun carrying T2 $(\mathrm{p}<.05)$, and youth who are both victims and engaging in violent behavior are $218 \%$ more likely to initate gun carrying T2 $(\mathrm{p}<.001)$.

$$
\text { //***Table } 3 \text { about here***// }
$$

Figure 2 is a second Venn Diagram that gives the ratio (and percent) of youth who initiated gun carrying $\mathrm{T} 2$ for each of the four possible combinations of violent victimization $\mathrm{T} 1$ and violent behavior T1. About one out of five (19\%) who were both victims of violence T1 and engaging in violent behavior T1 initiated gun carrying T2. About 16\% of youth who were only victims of violence T1 initiated gun carrying T2. Finally, about 9\% of yout who were only engaging in violent 
behavior T1 and 5\% of youth who were neither victims nor engaging in violent behavior T1 initiated gun carrying T2. Figure 2 reinforces the key findings from equation one in Table 3. Youth who were both a victim and engaging in violent behavior T1 were most likely to initiate gun carrying T2, followed by youth who were victims of violence only 1 , and youth who were only engaging in violent behavior T1.

$$
\text { //***Figure } 2 \text { about here***// }
$$

Equation two in Table 3 examines the relative likelihood of offensive versus defensive gun carrying among MYS youth. To determine if victims of violence T1 (defensive gun carriers) are more (or less) likely to initiate gun carrying T2 compared to youth who engage in violent behavior T1 (offensive gun carriers): (1) youth who were neither victims nor engaging in violent behavior, which are slightly over $50 \%$ of the cases in equation one, were excluded from the analysis in equation two; and (2) youth who engaged in violent behavior T1 was made the comparison group. The results in equation two show a pattern of non-significant findings. In other words, there is no statistically significant difference in the likelihood of initiating gun carrying T2 for victims of violence T1 compared to youth who engaged in violent behavior T1 (purely offensive versus purely defensive gun carriers).

\section{SUMMARY AND CONCLUSION}

Both criminologists and public health researchers have recognized that violence is a common experience for youth living in economically disadvantaged, urban neighborhoods (Acosta et al., 2001; Cook \& Laub, 2002). However, we could not identify any longitudinal studies that have examined the developmental sequencing between violent victimization, violent behavior, and gun carrying among adolescents, which is surprising given the prevalence of gun related violence in high poverty neighborhoods. The initiation of gun carrying was the focus of our study to disentangle the effects of violent victimization, violent behavior, and gun carrying. Our overarching goal was to 
increase our understanding of the precursors of gun carrying among youth as a step toward primary prevention of gun related violence. Routine activities theory was used as a framework to categorize violent victimization and violent behavior as risk factors and different motivations for initiation of gun carrying in high poverty neighborhoods. Analyses using two waves of longitudinal data from a high poverty sample of inner city youth (MYS) were conducted to determine: (1) if violent victimization and/or violent behavior T1 increased the likelihood of initiation of gun carrying T2; (2) the extent of overlap between victims of violence and youth engaging in violent behavior; and (3) the independent effects of violent victimization and violent behavior on initiation of gun carrying, which represent a range of youth who initiate gun carrying for purely defensive reasons (victim only T1), purely offensive reasons (violent behavior only T1), or a combination of both (both victim and violent behavior T1).

In the first part of the analysis, logistic regression was used to determine if violent victimization T1 and/or violent behavior T1 were risk factors for initiation of gun carrying T2 net of controls for age, sex, family structure T1, and gang membership T1. The findings indicate that both are significant risk factors for initiation of gun carrying. Since previous studies typically examined violent victimization without including controls for violent behavior T1 (or vice versa), this set of findings provided support for both sides of the gun control debate. In other words, youth who are motivated to carry guns for defensive (victims of violence) and offensive (violent youth) purposes are more likely to initiate gun carrying. However, when both violent victimization T1 and violent behavior T1 are examined simultaneously, then only youth who were victims of violence were significantly more likely to initiate gun carrying T2 (see equation three in Table 2).

In the next stage of the analysis, the overlap between victim and offenders was examined. The political debate surrounding gun control typically is polarized into an "either/or" dichotomy between defensive and offensive gun carrying. However, researchers over the past three decades 
have documented a large overlap between victims and offenders (e.g., Singer, 1981), which suggests that there are a large number of youth who carry guns for both defensive and offensive reasons. More importantly, these youth have not been the focus of previous longitudinal studies of gun carrying among youth. There were several objectives for this part of the analysis. One objective was to illustrate the level of overlap between victim of violence and youth engaging in violent behavior. A second objective was to identify the prevalence of purely defensive (victim only T1), purely offensive (violent behavior only T1), or a combination of offensive and defensive (both victim and violent behavior T1) gun carrying in this high poverty sample of minority youth. Youth who are victims only are the smallest group (4.9\%), followed by both victims and violent behavior (11.6\%), and only violent youth $(31.2 \%)$.

Table 3 contains the final stage of the analysis, which examined the independent effects of violent victimization and violent behavior on initiation of gun carrying. The multivariate results of the more detailed breakdown of the impact of violent victimization and violent behavior T1 on the initiation of gun carrying T2 indicate: (1) youth who are victims only T1, engaged in violent behavior only T1, or who were both victims and engaged in violent behavior T1 were respectively 238\%, $90 \%$, and $218 \%$ more likely to initiate gun carrying T2 compared to youth who are neither victims of violence nor engaged in violent behavior T1 (see equation one in Table 3); and (2) there was not a statistically significant difference between youth who initiated gun carrying T2 due to offensive (violent behavior only T1) or defensive (victim of violence T1 only) purposes (see equation two in Table 3).

\section{THEORETICAL AND POLICY IMPLICATIONS}

The starting point for this paper was the lack of longitudinal studies of gun carrying among youth that examined both victimization and violent behavior, which represent different motivations

for gun carrying. The findings highlight the key role of the combination of violent victimization and 
violent behavior on gun carrying among urban youth living in extreme poverty. Since researchers have not examined these factors simultaneously, it is difficult to determine if the findings from previous tests are an artifact of model misspecification. More specifically, Table 2 clearly illustrates that violent victimization (equation one) and violent behavior (equation two) are both risk factors for initiation of gun carrying, which provides empirical support for both sides of the gun control debate. However, an examination of violent victimization T1 and violent behavior T1 simultaneously revealed that only violent victimization T1 increased the likelihood of initiation of gun carrying T2 (equation three in Table 2). In short, violent victimization is a more robust predictor of initiation of gun carrying than violent behavior, which shows that purely defensive gun carrying is a key explanatory factor for first time gun carriers in high poverty settings. The more nuanced analyses conducted in equation one in Table 3 showed that either victimization or violent behavior T1 increased the likelihood of initiation of gun carrying T2 using "neither" as a comparison group. However, there was not a statistically significant difference between the likelihood of youth who initiated gun carrying T2 for offensive (violent behavior only T1) versus defensive (violent victimization only T1) purposes (see equation two in Table 3).

The rationale of focusing on initiation of gun carrying was to establish the developmental sequencing between victimization and violent behavior on gun carrying. A secondary goal was to identify the independent effects of victimization and violent behavior given their overlap. The overarching goal of policymakers developing gun violence prevention/intervention programs should be to reduce violent victimization and violent behavior among adolescents. As a result, targeted interventions should pay special attention to youth at risk for either violent victimization or violent behavior in an effort to break the progression from long term residence in violent neighborhoods, violent victimization and violent behavior, and gun carrying by adolescents as a logical response to high levels of violence in high poverty settings. The overlap between victims and offenders has 
theoretical relevance for developmental criminologists interested in precursors to gun carrying among urban youth over time, practical relevance for public health researchers who are focused on primary prevention of gun related violence, and policy relevance for researchers in a variety of fields who are attempting to develop interventions to leverage limited resources by targeting the most atrisk youth living in extreme poverty. However, this study did not uncover any differences between offensive versus defensive gun carrying once youth who were neither victimized nor violent offenders were excluded from the analysis. These analyses demonstrated that the polarization of the issue of gun carrying as offensive versus defensive is not as important as the role of violence in the community on gun carrying among youth living in extreme poverty.

\section{FUTURE DIRECTIONS}

Although this paper is a first step in understanding the role of violent victimization and violent behavior on gun carrying among urban youth, there are several potential areas for future research. First, the CCA approach suggests that the determinants of initiation of gun carrying are not necessarily the same as the determinants of stable gun carrying over time longer time periods (Steinman \& Zimmerman, 2003). Future research should also examine the interrelationship between violent victimization, violent behavior, and gun carrying over longer time periods to increase our understanding of the role of the timing of violent victimization and violent behavior (which came first?) on initiation of gun carrying (Spano et al., 2006).

Second, future studies should examine the role of other factors to rule out potential "third variables" that could account for our pattern of findings. More specifically, gun ownership by family members and/or peers who are not necessarily gang members were not examined in the current study, but have been identified as key determinants of gun carrying in previous studies (Lizotte et al., 2000). The MYS included gang membership as a control in the multivariate analyses as a proxy 
for gun carrying by peers, but did not include measures of the source of access and socialization for gun carrying by MYS youth.

Fear of crime was also included as a control variable in the multivariate analyses, but future research should determine if perceived risk of violent victimization and/or broader measures of exposure to violence in the community are key determinants of the initiation of gun carrying by youth living in extreme poverty (Spano et al., 2008; Spano et al., 2010). For example, exposure to violence includes vicarious victimization of family members or friends that are more common occurrences than violent victimization of MYS respondents. By focusing on exposure to violence, future researchers will be able to better specify defensive gun carrying by youth who are not victims of violence, but have family members of friends who have been victims of violence.

Finally, family structure T1 was included as a control variable in the multivariate analyses, but future research should examine the role of more nuanced aspects of parenting, which have been identified as a key explanatory factor in studies of adolescent development (Steinberg, 2001) that include studies of violent victimization (Spano \& Nagy, 2005; Spano \& Freilich, 2009) as well as violent behavior (Spano et al., 2009). Since parenting practices have been identified as key determinants of violent victimization, violent behavior, and gun carrying, future studies should determine if parenting practices partially mediate the effects of violent victimization and violent behavior on gun carrying (for a similar example, see Spano et al. 2009).

In conclusion, this paper is a first step in disentangling the effects of violent victimization, violent behavior, and gun carrying among urban youth. Since violent victimization and violent behavior represent the dual consequences of the concentration of violence in high poverty neighborhoods, it is surprising that previous studies have not viewed gun carrying as a cause (youth gun violence) and consequence (violent victimization as a precursor to defensive gun carrying) of violence in the community. This paper focused on violent victimization and violent behavior as 
precursors to first time gun carrying as a first step toward the primary prevention of gun related violence. If violent victimization and violent behavior represent two sides of a coin, then policy makers and violence prevention initiatives need to address both issue to prevent gun related violence in high poverty neighborhoods.

The findings from this study suggest that one of the secondary benefits of broader violence prevention initiatives will be a reduction in (first time) gun carrying by youth. However, targeted interventions to reduce gun violence in high poverty settings should also focus on: (1) addressing additional risk factors associated with gun related violence (e.g., early onset of aggressive behavior, poor anger management skills, truancy) (Lizotte \& Sheppard, 2001); and (2) identifying programs that improve community cohesion and efficacy to maximize the likelihood that residents will take an active guardianship role to counteract the "push" to carry a gun due to the high rates of violent behavior and violent victimization in high poverty neighborhoods (Molnar et al., 2009). The challenge for future researchers will be to increase our understanding of the interplay between these interrelated phenomenon among high risk youth. Additional research should track youth over longer periods of time to disentangle the effects of violent behavior and violent victimization to increase our understanding of the developmental consequences of violence in high poverty settings on the lives of urban youth. More generally, future research should focus on the impact of violence in the community on gun carrying as well as other developmental outcomes that extend beyond adolescence and into adulthood. 


\section{REFERENCES}

Acosta, O. M., Albus, K. E., Reynolds, M. W., Sprigs, D., \& Weist, M. D. 2001. Assessing the status of research on violence-related problems among youth. Journal of Clinical Child Psychology, $30,152-60$.

Ash, P., Kellerman, A.L., Fuqua-Whitley, D., \& Johnson, A. (1996). Gun acquisition and use by juvenile offenders, Journal of the American Medical Association, 275, 1754-1758.

Blendon, J.T., Hemenway, D., Blendon, R.J., \& Benson, J.M. (1996). The polls: trends guns. Public Opinion Quartelry, 60, 634-649.

Blumstein, A., Cohen, J., \& Farrington, D.P. (1988). Criminal career research: its value for criminology. Criminology, 26, 1-35.

Brame, R. \& Paternoster, R. (2003). Missing data problems in criminological research: two case studies. Journal of Quantitative Criminology, 19, 55-78.

Bureau of Justice Statistics (2004). Results from the National Crime Victimization Survey, 19732003. Downloaded from http://www.ojp.usdoj.gov/bjs/cvict.htm.

Cao, L., Cullen, F.T., \& Link, B.G. (1997). The social determinants of gun ownership: selfprotection in an urban environment. Criminology, 35, 629-650.

Centers for Disease Control and Prevention. 2007 Youth Risk Behavior Survey. Available at http://www.cdc.gov/yrbss. Last accessed on November 12, 2009.

Cook, P.J. \& Laub, J.H. (2002). After the epidemic: recent trends in youth violence in the United States. In M. Tonry (ed.), Crime \& Justice: A Review of Research, Vol. 29, pp. 1-37, Chicago, IL: University of Chicago Press.

Cook, P. J., \& Ludwig, J. (2004). Does gun prevalence affect teen gun carrying after all? Criminology, 42, 27-54. 
Dodge, K.A. (2001). The science of youth violence prevention: Progressing from developmental epidemiology to efficacy to effectiveness to public policy. American Journal of Preventive Medicine, 20, 63-70.

Fagan, J. \& Wilkinson, D.L. (1998). Guns, youth violence, and social identity in the inner cities. In M. Tonry \& M.H. Moore (eds.), Youth Violence, pp. 105-188, Chicago, IL: University of Chicago Press.

Jensen, G.F. \& Brownfield, D. (1986). Gender, lifestyles, and victimization: Beyond routine activity. Violence \& Victims, 1, 85-99.

Kellam, S.G. \& Van Horn, Y.V. (1997). Life course development, community epidemiology, and preventive trials: A scientific structure for prevention research. American Journal of Community Psychology, 25, 177-188.

Kellerman, A.L., Lee, R.K., Mercy, J.A., Banton, J. (1991). The epidemiologic basis for the prevention of firearm injuries. Annual Review of Public Health, 12, 17-40.

Kleck, G. (1988). Crime control through the private use of armed force. Social Problems, 35, 121.

Lauritsen, J.D., Sampson, R.J., \& Laub, J.H. (1991). The link between offending and victimization among adolescents. Criminology, 29, 265-292.

Lizotte, A.J., Krohn, M.D., Howell, J.C., Tobin, K., \& Howard, G.J. (2000). Factors influencing gun carrying among young urban males over the adolescent-young adult life course. Criminology, 38, 811- 834.

Lizotte, A.J., Tersoriero, J.M., Thornberry, T.P., \& Krohn, M.D. (1994). Patterns of adolescent firearms ownership and use. Justice Quarterly, 11, 51-74.

Margolin, G. \& Gordis, E.B. (2004). Children's exposure to violence in the family and the community. Current Directions in Psychological Research, 13, 152-155. 
McDowall, D. (1995). Firearms and self-defense. Annals of the American Academy of Political and Social Science, 539, 130-140.

Piquero, A.R., Farrington, D.P., \& Blumstein, A. (2007). Key Issues in Criminal Career Research: New Analyses of the Cambridge Study in Delinquent Development. New York: Cambridge University Press.

Rivara, F. P. (2002). Understanding and preventing violence in children and adolescents. Archives of Pediatric \& Adolescent Medicine, 156, 746-747.

Sampson, R. J., \& Lauritsen, J. L. (1990). Deviant lifestyles, proximity to crime, and the offender-victim link in personal violence. Journal of Research in Crime and Delinquency, 27, 110-39.

Sheley, J.F., \& Wright, J.D. (1993). Motivations for gun possession and carrying among serious juvenile offenders. Behavioral Sciences \& the Law, 11, 375-388.

Singer, S.I., (1981). Homogeneous victim-offender populations: A review and some research implications. Journal of Criminal Law \& Criminology, 72, 779-788.

Spano, R. \& Freilich, J. D. 2009. An assessment of the empirical validity and conceptualization of individual level multivariate studies of lifestyle/routine activities theory published from 1995 to 2005. Journal of Criminal Justice. 37:3, 305-314.

Spano, R., Freilich, J. D. \& Bolland, J. 2008. Gang membership, gun carrying, and employment: Applying routine activities theory to explain violent victimization among inner city youth living in extreme poverty. Justice Quarterly. 25:381-410.

Spano, R. \& Nagy, S. 2005. Social guardianship and social isolation: an application and extension of lifestyle/routine activities theory to violent victimization of rural adolescents. Rural Sociology. 70: 414-437.

Spano, R., Pridemore, W.A., \& Bolland, J. 2010. Are exposure to violence and violent behavior precursors for initiation of gun carrying for poor, urban minority youth? Manuscript under review. 
Spano, R., Rivera, C., \& Bolland, J. 2006. The impact of timing of exposure to violence on violent behavior in a high poverty sample of inner city African American youth. Journal of Youth and Adolescence. 35:681-692.

Spano, R., Vazsonyi, A., \& Bolland, J. 2009. Does parenting mediate the effects of exposure to violence on violent behavior? An ecological-transactional model of community violence. Journal of Adolescence. 32, 1321-1341.

Steinman, K.J., \& Zimmerman, M.A.. (2003). Episodic and persistent gun-carrying among urban African-American adolescents. Journal of Adolescent Health, 32, 356-364.

Tark, J., \& Kleck, G. (2004). Resisting crime: the effects of victim action on the outcomes of crimes. Criminology, 42, 861-909.

Thornberry, T., Bjerrgaard, B., \& Miles, W. (1993). The consequences of high attrition in a panel study of delinquency. Journal of Quantitative Criminology, 9, 127-158.

Webster, D.W., Gainer, P.S., \& Champion, H.R. (1993). Weapon carrying among inner-city junior high school students: Defensive behavior vs. aggressive delinquency. American Journal of Public Health, 83, 1604-1608.

Wright, J.D., \& Rossi, P. H. (1986). Armed and considered dangerous: a survey of felons and their firearms. New York: De Gruyter. 


\begin{tabular}{|c|c|c|c|c|}
\hline Variables & Description & Mean & S. D. & $\mathrm{N}$ \\
\hline \multicolumn{5}{|l|}{ Dependent variables } \\
\hline Initiation of gun carrying (T2) & Have you carried a gun during the past 90 days $(1=$ yes $)$ & .08 & .28 & 1049 \\
\hline \multicolumn{5}{|l|}{ Independent variables } \\
\hline Violent victimization (T1) & $\begin{array}{l}\text { Prevalence of violent victimization measured by three items: (1) Were you threatened } \\
\text { with a knife or gun during the past } 90 \text { days? (2) Were you cut bad enough to see a } \\
\text { doctor in the past year? ( } 3 \text { ) Were you shot at during the past year? (4) Were you hurt in } \\
\text { a fight bad enough to see a doctor in the past year? (1=yes) }\end{array}$ & .17 & .37 & 1048 \\
\hline Violent behavior (T1) & $\begin{array}{l}\text { Prevalence of violent behavior measured by four items: (1) Have you been in a physical } \\
\text { fight someone in the past } 90 \text { days (a fight with hitting, kicking, or pushing)? (2) Have } \\
\text { you cut someone bad enough to require a doctor's visit in the past year? (3) Have you } \\
\text { fought with someone while drunk or high on drugs in the past } 90 \text { days? (4) Have you } \\
\text { had sexual intercourse with someone when they really didn't want to during the past } 90 \\
\text { days? (1=yes) }\end{array}$ & .43 & .49 & 1014 \\
\hline Victim only (T1) & Victim of violence, but not a violent offender $(1=y e s)$ & .05 & .22 & 995 \\
\hline Violent behavior only (T1) & Violent offender only, but not a victim of violence $(1=y e s)$ & .32 & .46 & 995 \\
\hline Victim and violent behavior (T1) & Both a victim and violent offender $(1=$ yes $)$ & .12 & .32 & 995 \\
\hline Neither (T1) & Not a victim of violence and not a violent offender $(1=$ yes $)$ & .52 & .50 & 995 \\
\hline \multicolumn{5}{|l|}{ Control variables } \\
\hline Age (T1) & Age of respondent (in years) $[$ range $=9-19]$ & 13.1 & 2.28 & 1069 \\
\hline Sex & Sex of respondent $(1=$ male $)$ & .42 & .49 & 1069 \\
\hline Family structure (T1) & $\begin{array}{l}\text { Do you live with someone like a mother and someone like a father all of the time? } \\
(1=\text { yes })\end{array}$ & .30 & .46 & 1069 \\
\hline Fear of crime (T1) & How much of the time do you feel unsafe in your neighborhood? $(1=$ all the time $)$ & .13 & .34 & 1062 \\
\hline Gang member (T1) & Are you currently involved in a gang? $(1=y e s)$ & .03 & .16 & 1063 \\
\hline
\end{tabular}


Table 2. Odds Ratios from Logistic Regression Analyses: The Effects of Violent Victimization T1 and Violent Behavior T1 on the Initiation of Gun Carrying T2.

\begin{tabular}{llcc}
\hline Variable & \multicolumn{2}{l}{ Likelihood of Initiation of Gun Carrying T2 } \\
\hline & $(1)$ & $(2)$ & $(3)$ \\
Violent victimization T1 & $2.32^{* * *}$ & ---- & $2.10^{* *}$ \\
Violent behavior T1 & ---- & $1.91^{* *}$ & 1.59 \\
Control variables & & & \\
Age (T1) & 1.07 & $1.11^{*}$ & 1.08 \\
Sex & $2.99^{* * *}$ & $3.39^{* * *}$ & $3.15^{* * *}$ \\
Family structure (T1) & $.48^{*}$ & $.49^{*}$ & $.50^{*}$ \\
Fear of crime (T1) & 1.43 & 1.55 & 1.28 \\
Gang member (T1) & $4.56^{* *}$ & $4.90^{* * *}$ & $4.51^{* *}$ \\
Intercept & $.02^{* * *}$ & $.01^{* * *}$ & $.01^{* * *}$ \\
Model Chi-square & $59.5^{* * *}$ & $60.9^{* * *}$ & $64.3^{* * *}$ \\
$\mathrm{~N}$ & 1015 & 990 & 971 \\
\hline
\end{tabular}

${ }^{*} \mathrm{p}<.05 ; * * \mathrm{p}<.01 ; * * * \mathrm{p}<.001$ 
Table 3: Odds ratios for impact of violent victimization and violent behavior T1 on likelihood of initiation of gun carrying T2: a more detailed breakdown

\begin{tabular}{lcc}
\hline Variable & Likelihood of Initiation of Gun Carrying T2 \\
\hline & $(1)$ & $(2)$ \\
Only victimization T1 & $3.38^{* *}$ & 1.81 \\
Only violent behavior T1 & $1.90^{*}$ & 1.75 \\
Both victim and violent behavior T1 & $3.18^{* * *}$ & \\
Control variables & & 1.05 \\
Age (T1) & 1.08 & $2.33^{* *}$ \\
Sex & $3.15^{* * *}$ & $.44 *$ \\
Family structure (T1) & $.51^{*}$ & 1.15 \\
Fear of crime (T1) & 1.33 & $4.99^{* *}$ \\
Gang member (T1) & $4.70^{* * *}$ & $.04^{* *}$ \\
Intercept & $.01^{* * *}$ & $27.8^{* *}$ \\
Model Chi-square & $65.8^{* * *}$ & 457 \\
N & 971 & \\
\hline
\end{tabular}

$* \mathrm{p}<.05 ; * * \mathrm{p}<.01 ; * * * \mathrm{p}<.001$ 
Figure 1: The overlap between victims of violence and youth who engage in violent behavior

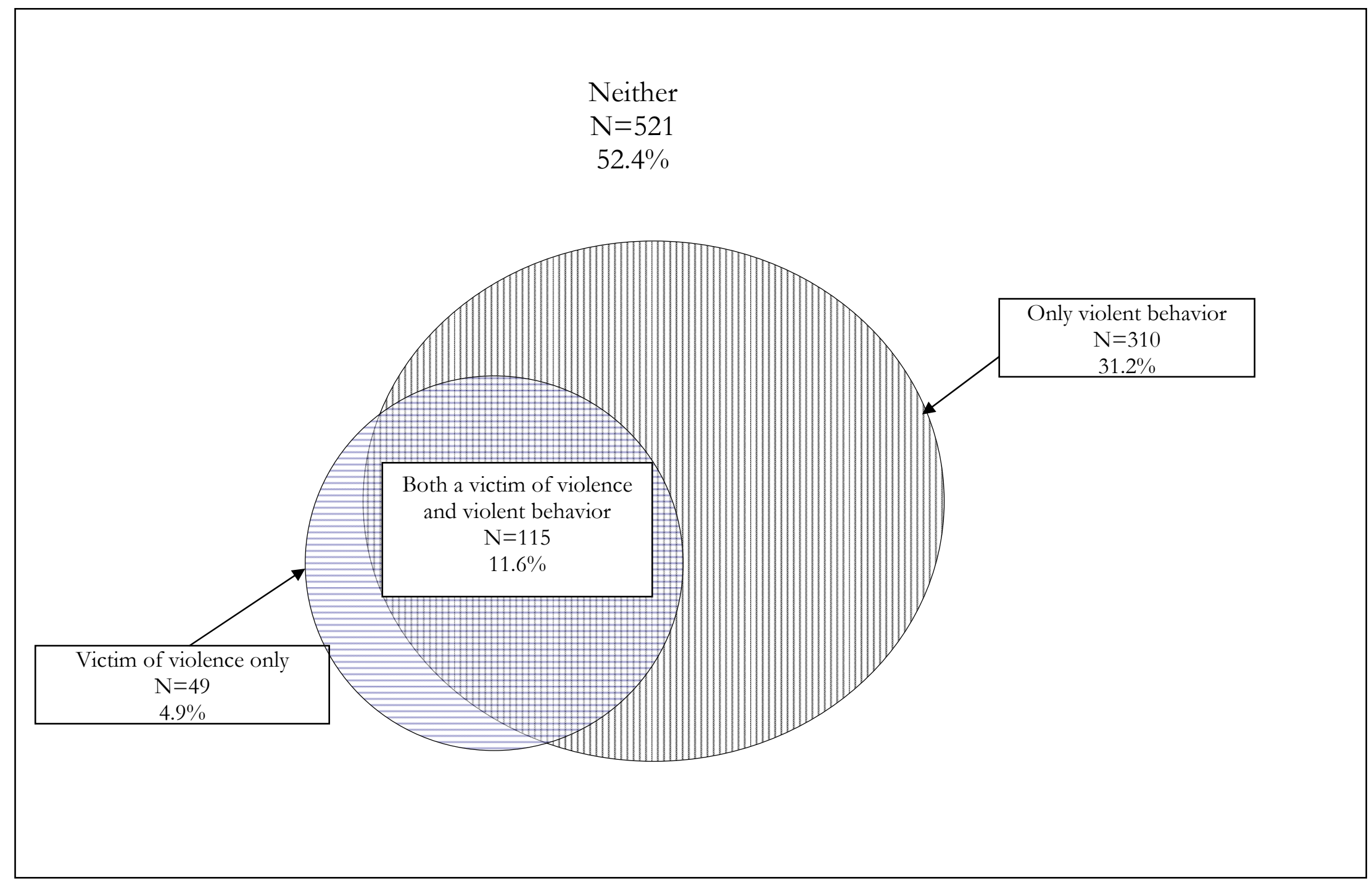


Figure 2: Ratio and percent of MYS youth who initiated gun carrying T2

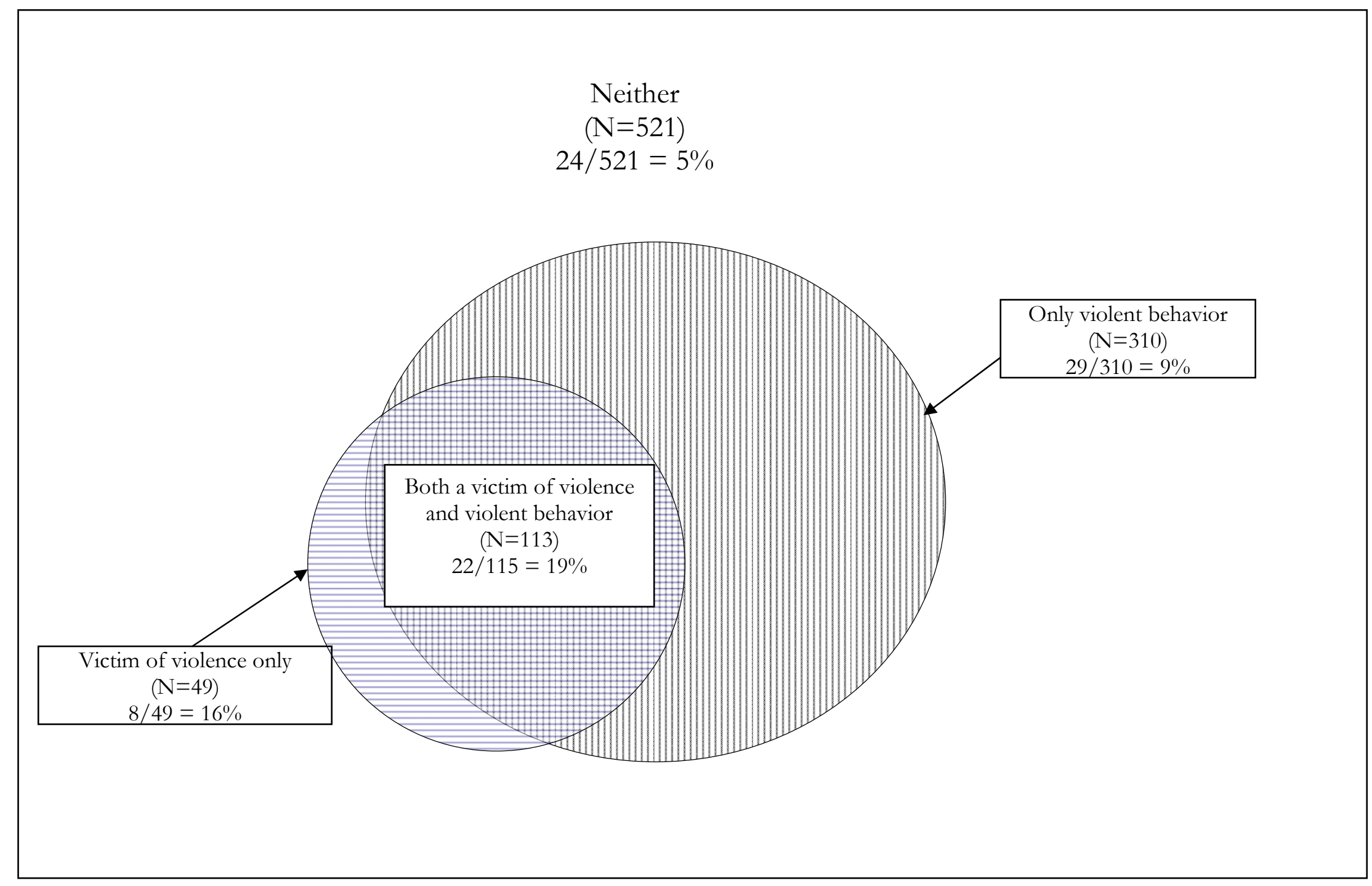

